\title{
THREE-DIMENSIONAL MOBILE MAPPING OF CAVES
}

\author{
Robert Zlot* and Michael Bosse \\ Autonomous Systems, CSIRO, Brisbane, Australia
}

\begin{abstract}
Existing methods of cave survey are time consuming and require significantly more time than naturally moving through the cave. The efficiency of these methods, even in the case of state-of-the-art laser-scanning technology, is fundamentally limited by the requirement that measurements be taken at static locations. We present a mobile approach to cave mapping, in which a lightweight 3D laser scanner is carried by a single operator while walking, climbing, or crawling through a cave at a natural pace. The mobility of the system means that it is straightforward and efficient to generate a high-resolution 3D map consisting of millions of points in almost any environment a human can reach. We present results demonstrating the technology in two cave systems located in different parts of Australia, what we believe are the first instances of mobile LiDAR mapping being utilized in natural caves.
\end{abstract}

\section{INTRODUCTION}

Traditional methods of cave mapping involve manual measurements of range and bearing between a sequence of stations typically spaced up to a few tens of meters apart (Warild, 2007, chap. 10; Kershaw, 2012). The most common instruments for measuring bearing are compass and clinometer, while for range, a fiberglass tape measure or topofil are commonly used. Detail is obtained through hand-drawn sketches of the local cave passage rendered at some or all of the stations, as well as left-right-up-down distance measurements to the walls, roof, and floor. The data are later merged into a cave map based on the registered survey station locations, often using computer software packages. These mapping techniques are not only highly time consuming, but rely on manual acquisition and recording of the measurements and sketches, which are prone to human errors including instrument-sighting error, station errors, and transcription errors (Hunter, 2010). Integrated systems such as DistoX (Heeb, 2008) can eliminate some of the manual sources of error by logging measurements directly from electronic instruments to a handheld mobile device, rather than paper. Recently, handheld laser distance meters have been increasingly employed instead of tape to acquire range measurements between survey stations (Dryjanskii, 2010). Theodolite systems have long been utilized in some instances (Middleton, 1991; Davis and Land, 2006; Rüther et al., 2009), but are considered too cumbersome or impractical for many cave survey applications due to their size, fragility, and weight (Warild, 2007; Slavova, 2012).

One of the most compelling recent examples of traditional cave surveying is the Jenolan Caves Survey Project (James et al., 2009). This project produced a tremendously comprehensive 3D model of the caves using data primarily acquired with total station and laser distance measurements. To improve the resolution of the model in areas with large voids, distance measurements were taken in twelve-point cross sections spaced at $10 \mathrm{~m}$ intervals. While the resulting model is highly detailed and accurate, an extraordinary amount of surveying and data processing effort was invested in the multi-year project, which was carried out between 1987 and 2005.

In recent years, terrestrial laser scanning, or LiDAR, technology has been used to create high-resolution 3D maps of a number of caves (e.g., Rüther et al., 2009; McIntire, 2010; Sadier et al., 2012). Terrestrial scanners are typically mounted on a stationary tripod and acquire millions of precise range measurements of the surfaces surrounding the station over a period of a few minutes. Data from multiple stations can be combined if there is sufficient overlap between the scanned surfaces, though in practice it is more common to measure the station position and orientation using standard surveying techniques, or to place known targets into the scans (Rüther et al., 2009). Despite the high quality of the data resulting from terrestrial LiDAR, the technique has seen relatively limited use in caves, most likely due to the high cost of the scanners, as well as the size, weight, and fragility of the equipment making it difficult to transport through difficult terrain and tight squeezes. In addition, the often complex geometry of caves may prescribe that a large number of scans be acquired to achieve sufficient coverage and avoid shadows due to occlusion. McIntire (2010) reports, "the most time-consuming part of the scan was moving from station to station and shooting in the targets. ... Every setup was a challenge to determine where the previous and upcoming scans' shadows would occur and locating the best combination of scan coverage and setup efficiency."

Mobile mapping is a technique whereby measurements of the environment are acquired while moving continuously through it. Commercial solutions exist that acquire LiDAR scans from moving aircraft, watercraft, or street vehicles (Petrie, 2010); however, these systems typically rely on expensive, bulky equipment and on global navigation satellite systems (GNSS) such as GPS for positioning. Mining applications have provided a market for transitioning mobile mapping technology underground. Due to the

\footnotetext{
*Corresponding Author: Robert.Zlot@csiro.au
}

Journal of Cave and Karst Studies, December 2014•191 
difficulty of operating without GNSS coverage, underground mine mapping has largely remained a research problem (Nüchter et al., 2004; Morris et al., 2006; Fairfield et al., 2010), and, with the exception of other recent work we have done based on technology similar to what is presented in this paper (Zlot and Bosse, 2014), no systems of which we are aware have been demonstrated to be capable of efficiently mapping a large-scale mine in $3 \mathrm{D}$. In any case, the platforms that have been fielded have been mounted on wheeled vehicles that rely on the existence of roadways in the mine and would be unsuitable for most natural caves. Indoor mobile mapping technology could also be considered relevant to mapping caves, but existing systems involve wheeled platforms (e.g., Canter and Stott, 2011) or require planar structures in the environment such as walls, floors, and ceilings (Liu et al., 2010).

To address some of the limitations of existing mobile mapping systems, we have developed portable LiDARbased mobile mapping technology that does not require external positioning or artificial infrastructure, is relatively inexpensive, and can easily be carried by hand by a single operator through the challenging environments presented by natural caves (Fig. 1). The raw data acquired are converted by software into globally consistent and metrically accurate $3 \mathrm{D}$ point clouds or surface models consisting of millions of points or triangles, as well as an estimate of the sensor trajectory through the cave. The combination of mobility and maneuverability facilitates efficient data acquisition, because a cave can be mapped in the time it takes to walk, crawl, squeeze, or climb through it; a high degree of coverage, because shadows due to occlusion are avoided by virtue of the motion; and versatility, because most terrains through which a human can traverse can be mapped. In addition, the system is fully automated, eliminating the human errors inherent to manual surveying techniques, despite requiring nearly zero training time. Easy acquisition of dense and accurate point cloud data can provide models useful not only for navigation, but also for a variety of scientific applications previously not possible or economical.

Our handheld mobile mapping system has been deployed in several cave and underground mine sites around the world. To our knowledge, our body of work represents the first instance of mobile mapping in nonsubmerged caves (Stone et al. (2000) and Gary et al. (2008) describe mapping underwater voids using sonar), and a significantly more efficient and complete method of surveying caves compared to the state-of-the-art. After describing the equipment and its use, we present results obtained from extensive scanning of significant parts of the Jenolan Caves and Koonalda Cave in Australia.

\section{EquipMent AND Methods}

The key enablers of our mobile cave mapping technology are a lightweight handheld laser-scanning device coupled with data processing software capable of accurately estimating the position and orientation of the scanner over time as it is moved through the environment. The scanner measures tens of thousands of ranges per second from the sensor origin to points on various physical surfaces using narrow infrared laser pulses. Given an accurate estimate of the scanner's motion, the set of range measurements can be projected into $(x, y, z)$ points in a common coordinate frame, thereby generating a consistent point cloud model of the cave and surrounds.

\section{The Zebedee Mobile Mapping System}

Zebedee (Fig. 1) is a handheld 3D mobile mapping system consisting of a 2D laser scanner mounted on a spring (Bosse et al., 2012). The infrared laser scanner is a Hokuyo UTM-30LX, which, at $370 \mathrm{~g}$, is light enough to be carried by hand. The UTM-30LX emits $905 \mathrm{~nm}$ laser pulses at a high frequency that reflect off surfaces in the environment and return to the sensor. The scanner internally converts the signal to a range measurement based on the time of flight. Within the scanner, the laser pulses are spread across a plane by a spinning mirror rotating at $40 \mathrm{~Hz}(100 \mathrm{~Hz}$ in the newest Zebedee hardware). Measurements are acquired within a field of view of $270^{\circ}$ at quarter-degree angular resolution, resulting in 43,200 points per second. The maximum range of the scanner is approximately $35 \mathrm{~m}$ in the cave environment and surfaces beyond that range are not registered as measurements. The range precision is typically 1 to $3 \mathrm{~cm}$, depending on the distance and incidence angle to the surface, as well as surface reflectivity.

A unique design feature of Zebedee is the spring on which the laser scanner is mounted. The purpose of the spring is to passively convert the natural motion of the operator carrying the device into rotational motion of the scanner. The non-deterministic, loosely swaying motion of the scanner typically results in a 150 to $180^{\circ}$ out-of-scanplane field of view. Sweeping the device in this manner effectively extends the inherent two-dimensional field of view of the Hokuyo scanner into a three-dimensional view of the environment acquired roughly every second.

A MicroStrain 3DM-GX3 industrial-grade microelectromechanical (MEMS) inertial measurement unit (IMU) is mounted beneath the scanner, and provides measurements of angular velocities and linear accelerations. The inertial measurements are used by the processing software, along with the LiDAR data, to estimate the scanner trajectory. The IMU also contains a three-axis magnetometer that can further aid the solution by constraining the absolute heading in environments with minimal magnetic interference, which is often the case in caves.

In addition to the handheld device, the Zebedee hardware system includes a small laptop for operating the sensors and logging data. A lithium-ion battery pack powers both the sensors and laptop. Batteries of various capacities are available; a $1 \mathrm{~kg}$ battery provides more than ten hours of operation. The laptop, power pack, and spare 

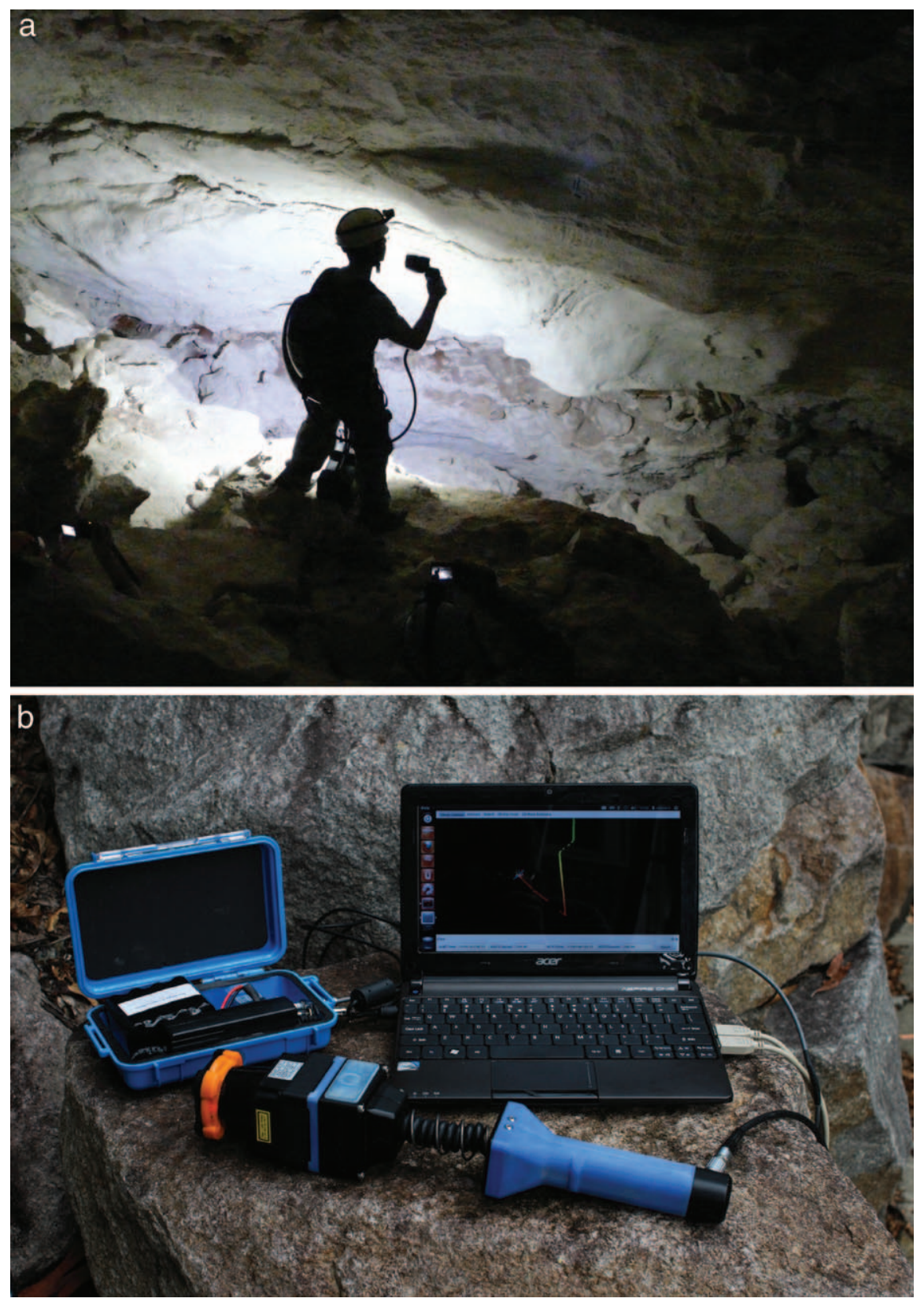

Figure 1. (a) Mapping Koonalda Cave with the Zebedee 3D mapping system. The scanning device is held in the operator's right hand, with a battery pack and small laptop for recording data carried in a backpack. (b) The components of the Zebedee system.

batteries are typically carried in a backpack, which can easily accommodate other tools and supplies. Operation can also be fully controlled and monitored via a smartphone interface, eliminating the need to access the laptop between datasets. To extend the operator's reach, a camera monopod can be connected to the bottom of the Zebedee handle via a standard 1/4-inch tripod screw socket.

\section{Data ACQuisition}

Data collection with Zebedee is a continuous procedure, but can be broken down into a number of manageable datasets, which are typically in the range of 10 to 90 minutes in duration. Acquiring data for an individual dataset involves powering up the equipment, starting the logging software using a web browser on a laptop or mobile device, picking up the scanning device, following a desired path, then putting down the device and terminating the logging process. If the objective is to merge multiple datasets into a global model, some repeated coverage is required between the scanned areas in order for the processing software to automatically detect the matching areas and align the point clouds. Typically a

Journal of Cave and Karst Studies, December 2014•193 
few meters of overlapping trajectory is sufficient. If multiple Zebedee units are available, multiple operators can simultaneously collect data in different areas to be combined later into a common map. The data acquisition software uses the open-source Robot Operating System (ROS) middleware platform, and stores the raw data in ROS-native .bag files at a rate of approximately $100 \mathrm{MB}$ every 7.5 minutes. The data processing software is run post-acquisition and outputs the $3 \mathrm{D}$ maps and trajectory followed in standard point cloud file formats, including .laz (compressed .las) and .ply. The size of a point-cloud file stored in .laz format is approximately $1 \mathrm{MB}$ for every 325,000 points, or about $7.75 \mathrm{MB}$ per minute of data, so a typical cave model is expected to be anywhere in the range of tens of megabytes to a gigabyte in size.

\section{Data Processing}

The very nature of mobile mapping involves a sensor platform that is continuously in motion as measurements are acquired. However, in order to generate a consistent map, all of the point measurements are required to be transformed into a common coordinate frame. Therefore, a mapping solution must be able to accurately estimate the trajectory of the laser scanner, a continuous function specifying the scanner's 3D position and orientation at all times during acquisition. Although there is no external positioning system available, the trajectory can be estimated based entirely on the LiDAR and inertial measurements. The challenge of concurrently estimating the trajectory of a sensor and a map of the environment is a fundamental problem known in the robotics literature as simultaneous localization and mapping, or SLAM (Durrant-Whyte and Bailey, 2006).

An essential requirement of SLAM solutions is the observation of features in the environment multiple times. As a simplified example of how motion can be estimated through external observations, imagine taking a singlepoint measurement of the distance to a wall. An initial measurement of $5 \mathrm{~m}$ is recorded, followed by a measurement of $3 \mathrm{~m}$ taken at a slightly later time. Assuming that the two measurements can be associated with the same physical surface, one can infer from these observations that in this time the sensor has moved $2 \mathrm{~m}$ in the direction perpendicular to the wall. By aggregating thousands of similar measurements of matched surfaces with various orientations in the observed environment, the $3 \mathrm{D}$ motion of the sensor can be estimated to a high degree of precision.

The algorithmic framework underlying the Zebedee trajectory estimation solution is based on a generalization of the above principle (Bosse et al., 2012). As the laser scanner swings about on the spring, it sweeps through its field of view, capturing a 3D scan of the local environment roughly once per second. Within a time window of a few seconds, there is a considerable amount of overlap between the parts of the environment scanned in each sensor sweep. Surface elements, which contain a position and normal direction, are extracted from local patches of scan points from within these sweeps. By matching pairs of surface elements acquired at distinct times, the trajectory between those samples is determined by the relation between the surface geometries. The inertial and magnetometer measurements are used to generate further constraints on the scanner trajectory over these short time windows. An optimization routine solves for the trajectory that minimizes the differences among the various constraints starting from an initial estimate derived from the inertial measurements. By shifting the time window at each time step, the trajectory of the scanner is incrementally generated as more data are captured.

As the trajectory length increases, small errors can build up, resulting in a drift of the solution over time. While these errors tend to be small, not addressing them would not only result in global inaccuracies, but also in point clouds with apparent fuzziness or doubling of surfaces due to multiple images of a surface observed at different times. There are also situations where there is a higher risk that large local errors could be introduced into the solution, such as very tight squeezes where the scanner has a limited view of the environment. The SLAM algorithm used for estimating the initial scanner trajectory can also be used to apply corrections to the trajectory by optimizing all of the data over an entire dataset rather than over a few-second time window. This non-rigid global optimization step applies small corrections along the trajectory that result in consistent, registered surfaces throughout the map. This process is somewhat analogous to applying loop closure constraints in a traditional survey. However, a key difference in this solution is that the loop closures do not occur at discrete stations (as there are no stations), but rather are detected automatically and continuously as parts of the environment are rescanned.

If the buildup of errors is relatively large (for example, in a large dataset), a place recognition algorithm can improve the input trajectory provided to the global optimization by identifying locations in the environment that have been scanned multiple times (Bosse and Zlot, 2013). Place recognition also provides the facility to automatically align multiple maps together, provided there is sufficient overlap, typically a few meters, among them. This capability is useful for merging data collected at different times or when multiple operators are scanning a cave system simultaneously.

The entire data processing pipeline is run automatically: The raw LiDAR and inertial measurement streams are taken as input, and a trajectory and 3D point cloud are generated as output. The processing time required to compute a solution is less than the time spent collecting the data; therefore it is possible to build a map in real-time during acquisition. More detailed technical descriptions of the algorithms are available in previous publications (Bosse et al., 2012; Bosse and Zlot, 2013; Zlot and Bosse, 2014). 


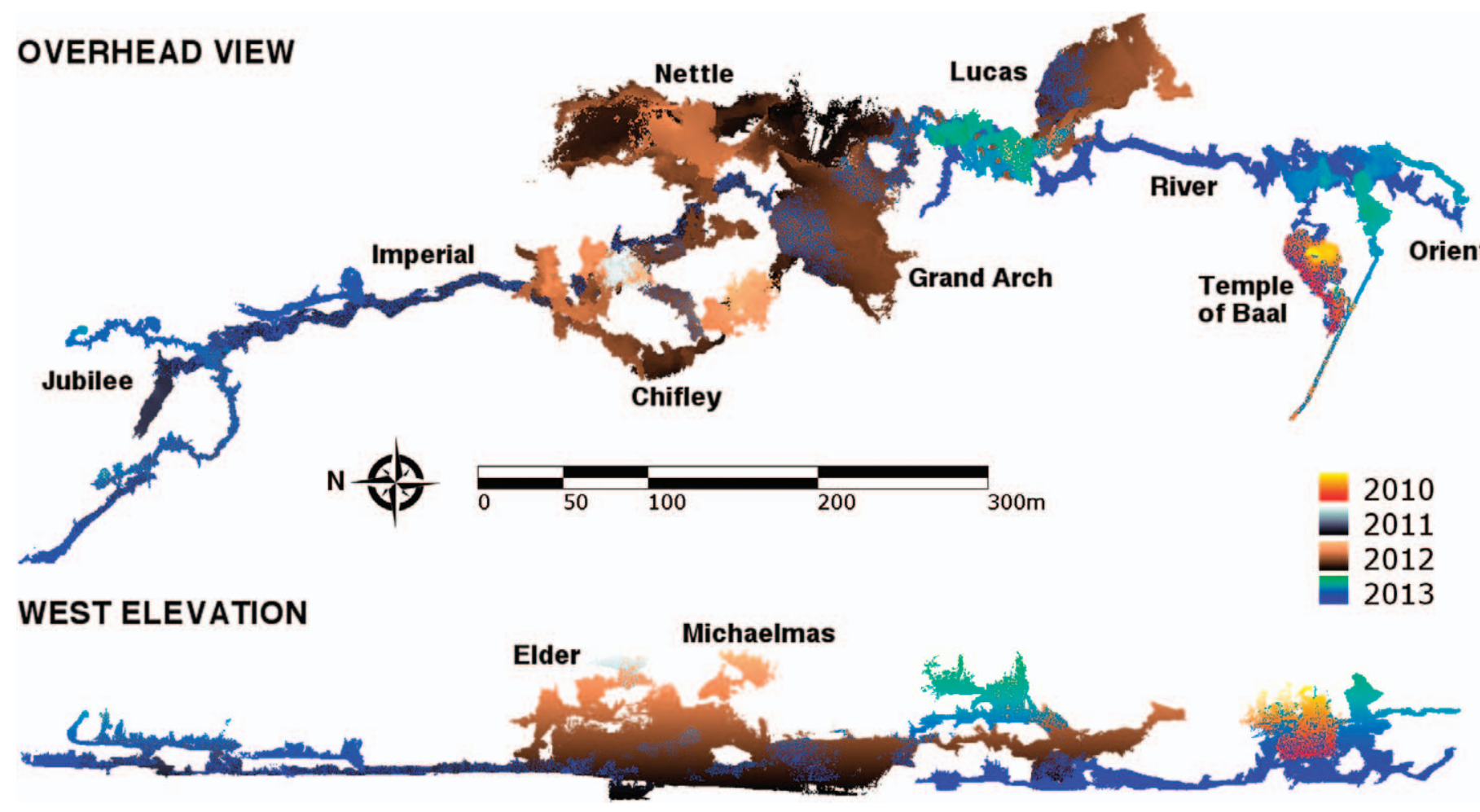

Figure 2. Three-dimensional point cloud map of the Jenolan Caves projected as overhead and elevation views. The map is generated from 15.5 hours of LiDAR data collected over four visits in 2010 (with Hannibal device), 2011 (Zebedee device), 2012 (Zebedee), and 2013 (Zebedee). A different colormap is used to color data from each trip according to elevation as indicated on the right side of the image. The full resolution point cloud from these datasets consists of over 2.7 billion points. Significant caves are labeled.

\section{RESULTS}

We have deployed our 3D mapping systems in several caves around the world. Here we describe the most significant undertakings and results from the Jenolan Caves and Koonalda Cave in Australia.

\section{JenOlan CAves}

The Jenolan Caves are located in New South Wales, approximately $110 \mathrm{~km}$ west of Sydney. A recent study has dated some areas of the caves to be 340 million years old, making Jenolan the oldest complex cave system accessible to humans (Osborne et al., 2006). The Jenolan system consists of a number of interconnected caves generally running in a north-south direction and at various levels vertically (Fig. 2), with several of the entrances located at the Grand Arch. The caves extending a kilometer to the south of the Grand Arch contain several large chambers connected by a series of passages, the longest of which includes an underground river flowing through a passage below Lucas, Temple of Baal, and Orient Caves. To the north of the Grand Arch, the caves are generally contsist of long passages and relatively narrower local voids. A wide variety of attractive speleothems are present throughout many of the caves. The Jenolan Caves are a popular tourist attraction, and a number of the caves have been converted into show caves with paved pathways, stairs, handrails, and lighting. Other caves have generally been left in their natural state, containing rugged terrain and tight squeezes.

Our initial involvement in mapping the caves was to support research being conducted by researchers at the Australian Nuclear Science and Technology Organization (ANSTO). ANSTO is investigating the use of speleothem composition and growth patterns for interpreting the palaeo-climatic record through measurement and analysis of isotopes (Waring et al., 2009). Various sensors have been placed in several of the caves to monitor the composition of gases, drip water, and air flow. Large-scale, high-resolution $3 \mathrm{D}$ volumetric models are necessary to more accurately model air flow and growth patterns through the cave system.

Our first mapping trip to the Jenolan Caves took place over two days in September 2010. At the time, the Zebedee system was in a very early stage of development and was not ready for deployment. However, the initial requirements specifically involved mapping several of the tourist show caves, which contain paved pathways and stairs. Therefore, we constructed a wheeled mobile-mapping platform, called Hannibal, consisting of hardware that

Journal of Cave and Karst Studies, December 2014•195 


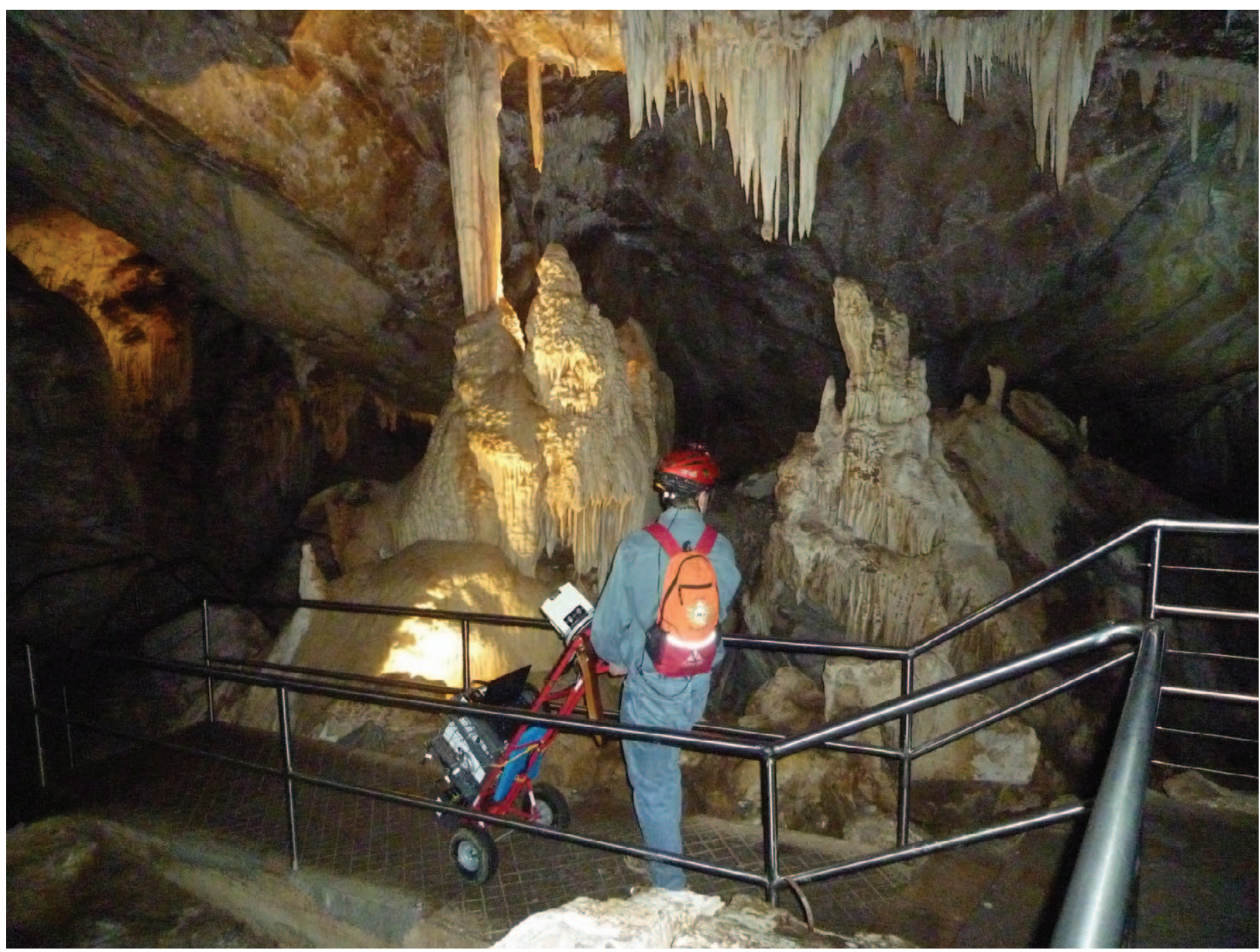

Figure 3. The Hannibal mapping cart in operation in Lucas Cave, Jenolan.

had previously been developed for use on vehicles. This system used a motorized platform to spin a $2 \mathrm{D}$ laser scanner at a constant rate (Bosse and Zlot, 2009). The scanner, a SICK LMS291, measures ranges in a plane, similar to the Hokuyo, with several key differences in the specification, most notably a significantly increased mass at $4.5 \mathrm{~kg}$. In addition, the LMS291 scans at $75 \mathrm{~Hz}$, producing 180 points per scan within a $180^{\circ}$ angular range, and has with an $80 \mathrm{~m}$ maximum range. By continuously rotating the scanner about the center scan ray at $30 \mathrm{rpm}$, a hemispherical 3D field of view containing 13,500 points is obtained once per second. The spinning LiDAR system is mounted to an upright, two-wheeled furniture cart $1.3 \mathrm{~m}$ in height and $54 \mathrm{~cm}$ wide (Fig. 3). A MicroStrain 3DM-GX2 IMU is rigidly mounted to the cart, providing measurements of angular velocity and linear acceleration at $100 \mathrm{~Hz}$ used to provide additional reliability as well as stabilization of pitch and roll angles with respect to gravity. At the bottom end of the cart are three racks storing sealed leadacid batteries, electronics, and a small netbook for controlling the sensors and data logging. As the system's overall mass is approximately $60 \mathrm{~kg}$, a considerable physical effort is required, often by two people, to move the cart up and down long stairways. Data acquired from Hannibal are processed with the same core software used for Zebedee data.

Over the course of two days, we collected data over a path length of more than $9 \mathrm{~km}$ within Chifley, Imperial, Lucas, Temple of Baal, and Orient Caves, as well as several areas of the surface above and between the entrances of the caves. The total acquisition time was just under ten hours at an average speed of $0.7 \mathrm{~km} / \mathrm{h}$ inside the caves. In a very small number of areas the footpaths or stairways became too narrow, and Hannibal was briefly raised and carried by two or more people for a few meters.

A number of stations from previous surveys (James et al., 2009) are marked in the ground surface of the caves using stainless steel disks. We therefore elected to incorporate the station coordinates into our solution for added reliability and georeferencing. To do so, we simply 


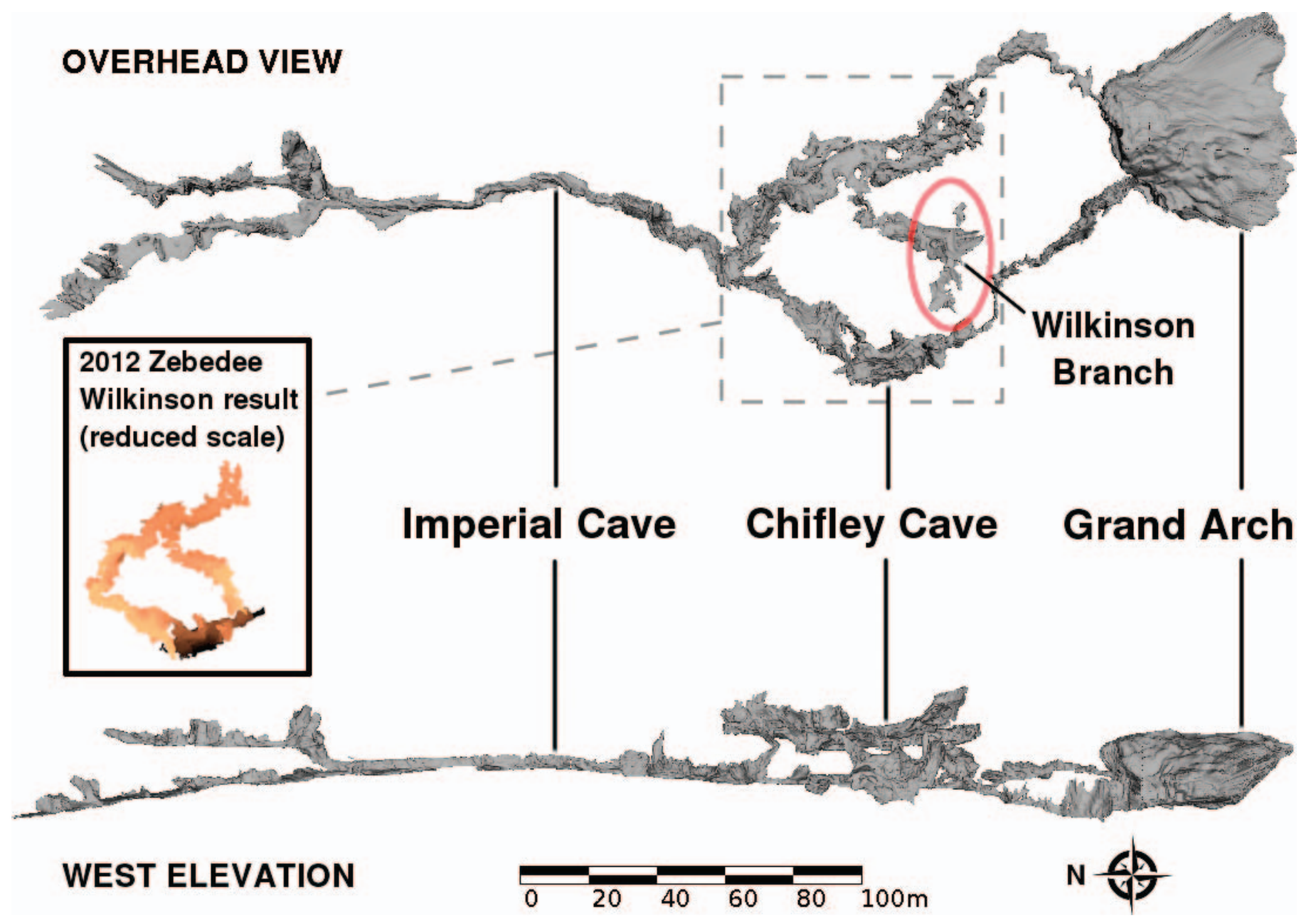

Figure 4. Detailed 3D watertight surface model of Chifley and Imperial Caves generated from LiDAR data acquired from the Hannibal platform. Chifley is a C-shaped passage at a level approximately $10 \mathrm{~m}$ above Imperial. While scanning the Wilkinson Branch, data were lost for about 30 seconds due to a USB cable becoming unplugged. The data loss resulted in a kink in the trajectory, indicated by the red circle. Rescanning of this section with Zebedee in the 2012 visit has produced a corrected model of this area (see callout box).

stopped the cart directly above any survey markers seen on the ground, leaving the equipment stationary for approximately ten seconds. These events are then straightforward to identify later in the data stream as stationary points in the trajectory. A matching step found a geometric transformation between the trajectory and the ground control points, which were then used as loose constraints within the non-rigid optimization algorithm. Due to its continuous motion, it is not as straightforward to stop Zebedee at survey stations. We are currently experimenting with methods to allow us to automatically detect when we are at one of these points to enable georeferencing of Zebedee data in a similar manner.

In addition to the point cloud models produced, watertight surface models were required for use in the researchers' air flow analysis. Software for generating 3D surface models from the point clouds was developed for this purpose (Holenstein et al., 2011). One reality of mapping with this equipment in confined spaces is that it is inevitable that members of the mapping team will occasionally need to enter the scanner's field of view, thereby introducing spurious points into the point cloud. These spurious points can be removed during surface reconstruction by modeling each measurement as a spacecarving ray. If a ray successfully passes through the location of a point at other times, then the point can be disregarded as coming from a moving object. One disadvantage of converting the point cloud data to a smooth surface in this manner is that much of the fine structure of the cave features is lost in the surface model. An example surface reconstruction from Chifley and Imperial caves is illustrated in Figure 4. Detailed watertight surface models can be fabricated into physical scale models using 3D printing technology (Baselgia et al., 2014).

Although successful, clearly the size, weight, and wheeled base of Hannibal suggest that it is unlikely to be 


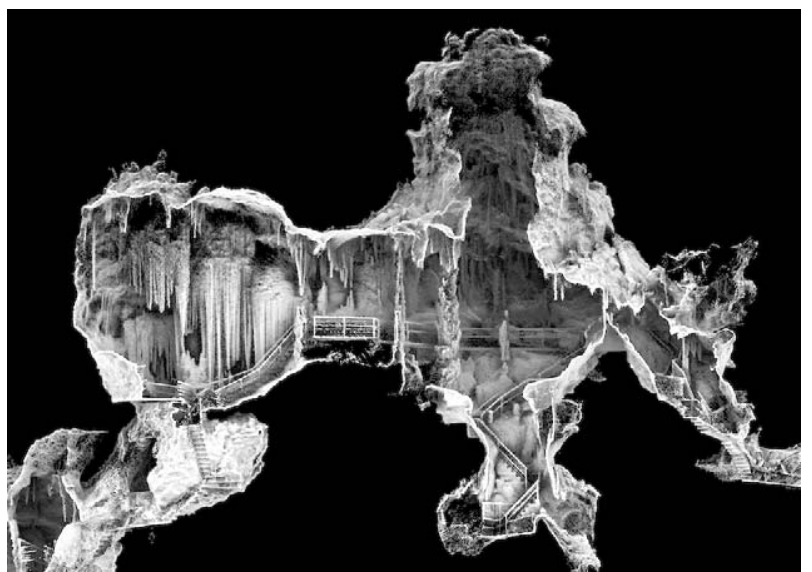

Figure 5. Point cloud of a section of Orient Cave. Some of the wall surfaces have been cut away to reveal natural formations, platforms, staircases, and handrails.

appropriate for the vast majority of natural caves. However, this initial deployment only required access to paved pathways and stairs in show caves, which, with some physical effort, is achievable. The platform also served as a proof-of-concept for LiDAR-based mobile mapping in natural caves and further motivated the development of the more practical Zebedee system.

Subsequent trips to the Jenolan Caves, with Zebedee systems, occurred in August 2011, November 2012, and May 2013. In 2011, several caves were scanned, including Orient, River, Pool of Cerberus, Lucas, Imperial, Jubilee, and Elder caves. In 2012, Chifley, Imperial, Nettle, Elder, and Michaelmas caves were mapped, as well as several kilometers of paths on the surface outside and above the caves. In 2013, Orient, Baal, Lucas, River, and Jubilee caves were scanned. On the latter two trips, multiple Zebedee units were available, allowing different areas to be mapped simultaneously and later automatically combined by the processing software. Figure 2 shows a combined map merging a subset of the data from the 2011-2013 scans of Jenolan; some of older, redundant data and a few areas on the surface have been excluded. Data from the Temple of Baal cave scanned with the Hannibal cart system in 2010 are also included in the figure, as the height of the main chamber is beyond the maximum range of Zebedee's laser scanner. The result illustrated is based only on the LiDAR data and does not incorporate any ground control points from previous surveys. A close-up of a section of the Orient Cave point cloud generated with the Zebedee system is presented in Figure 5.

Key data collection statistics for the model presented in Figure 2 are presented in Table 1. Overall, the map includes about 15.5 hours of cave scanning, collected over $17.1 \mathrm{~km}$ of traverse. It should also be noted that there was a higher than required degree of overlap between the datasets, so the total scanning time and trajectory length could be significantly reduced while still achieving the same coverage. We estimate that two operators familiar with the cave layout could cover the same area in a single day. Within the show caves, the average rate of traverse using Zebedee was $1.7 \mathrm{~km} / \mathrm{h}$, approximately 2.5 times the average speed achievable with Hannibal.

The Zebedee system is not limited to tourist show caves containing pathways, platforms, and stairs. Even in the case of the show caves, many sections could not have been navigated with Hannibal due to steep stairs, ladders, narrow passageways, and rough or muddy terrain. In addition, the terrain in other caves that were covered is more natural. For example, Elder and Michaelmas Caves primarily consist of small chambers connected by narrow passages and squeezes. A detailed view of the 3D model of Elder Cave is presented in Figure 6. The terrain in Elder Cave is relatively rugged, requiring scrambling, squeezing, and climbing to traverse it. The cave generally runs vertically from a sinkhole opening at the surface down to a connection with Imperial Cave. Our 2011 traverse followed this route, including scanning while abseiling down the sinkhole. In 2012, the route started from below, ascending to the sinkhole, and then back down to Imperial along a slightly different path, taking about two hours in total. At a few of the most challenging squeezes and climbs, the Zebedee unit was passed through the opening to a second person to allow the primary operator use of both hands. These hand-offs could be completed without interrupting the datastream, thus there are no breaks in the map. The point cloud model of Elder Cave can also been seen as part of the overall model of the Jenolan Caves in Figure 2, where it matches with Imperial Cave at the bottom and the sinkhole area as scanned from the surface above. The results from Elder Cave highlight the versatility

Table 1. Key statistics from Jenolan Caves datasets included in the model shown in Figure 2.

\begin{tabular}{lccc}
\hline Trip Year & Total Path $^{\mathrm{a}}, \mathrm{km}$ & Cave Path $^{\mathrm{b}}, \mathrm{km}$ & Cave Time $^{\mathrm{b}}, \mathrm{h}: \mathrm{min}$ \\
\hline 2010 & 0.4 & 0.4 & $0: 49$ \\
2011 & 2.2 & 2.2 & $1: 33$ \\
2012 & 11.4 & 5.3 & $4: 56$ \\
2013 & 11.4 & 9.1 & $8: 08$ \\
Total & 25.5 & 17.1 & $15: 26$ \\
\hline
\end{tabular}

\footnotetext{
${ }^{\text {a }}$ Total Path indicates trajectory length combining both cave and exterior datasets.

${ }^{\mathrm{b}}$ Cave Path and Cave Time refer to the trajectory length and scanning duration within the caves (excluding exterior datasets).
} 


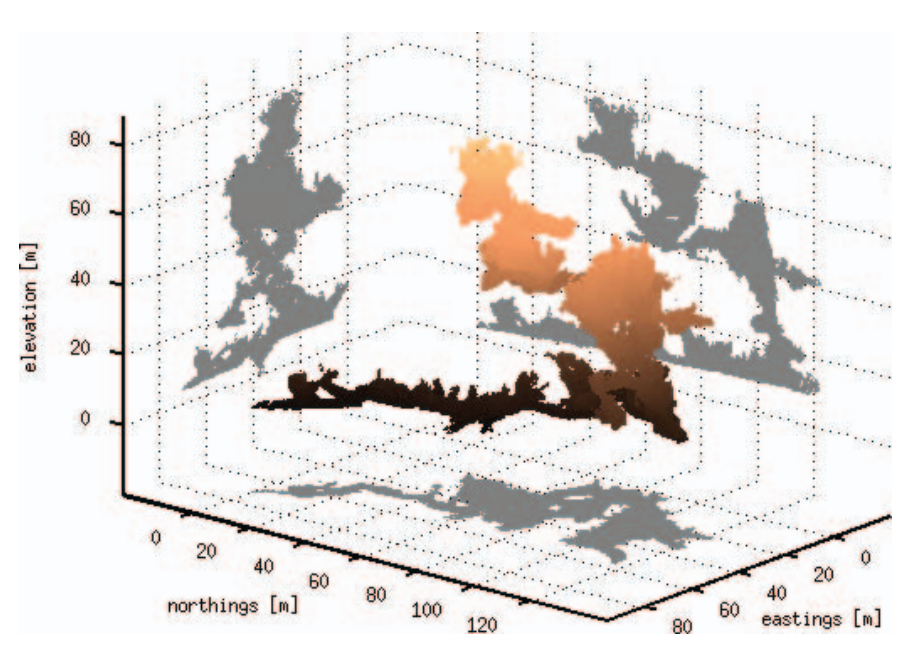

Figure 6. Point cloud map of Elder Cave generated from the 2012 data. The 3D representation at center is colored by height. Projections onto the axis-aligned planes are shown in grey. At the uppermost region of the model is the sinkhole opening to the surface. The long passage at the bottom is part of Imperial Cave. The actual resolution of the data is higher than the resolution of this display.

and robustness of the system in mapping more challenging cave environments.

The Jenolan Caves had previously been the subject of extensive surveys using more traditional methods. In Figure 7, the Zebedee-generated model is compared to a map completed in 1925 by Oliver Trickett (Middleton, 1991) and with 59 survey stations from the more recent Jenolan Caves Survey Project (James et al., 2009). The layout of the caves is generally in agreement with the previous surveys, though there are some clear misalignments between the outlines. The most obvious discrepancy can be seen on the left side of the image, where accumulating yaw drift along a $500 \mathrm{~m}$ branch of Imperial and Jubilee Caves has introduced a large error. In this case, one of the datasets covering this section of Imperial was collected in 2011, using an older version of the acquisition software in which no magnetometer data was recorded and timing information was less accurate. As a result, there is increased drift error, and without an opportunity to close the traverse, there are no constraints to correct the error. We plan to rescan this section in an upcoming trip, which we expect would improve this area of the model. Elsewhere in the cave system, the differences are of a much smaller magnitude, and the fact that the majority of the survey station markers fall within the Zebedee map outline show that the models agree to within a few meters. In general, the Zebedee maps are locally accurate, and it is primarily over large open traverses that the relative error can become significant. Although the absolute accuracy of the traditional surveys appear to be superior, the advantages of the Zebedee system are that the results can be produced much more efficiently, within a day or two for Jenolan; automatically, as the required operator expertise is minimal; and at a much higher resolution, billions of measurements rather than hundreds or thousands.

The drift error apparent in the branch through Imperial to Jubilee Cave in Figure 7 is indicative of potential system performance in situations where the only way to survey a cave or passage is by following a long, open traverse (i.e., where it is not possible to close a loop). We can quantify the drift by comparing the open-loop trajectory from the first phase of processing to the trajectory from the final optimized model in places where there are loops available. The analysis is carried out by calculating the difference between fixed-length segments of the open and closed trajectories of the Zebedee handle (which reflects the distance the operator has walked rather than the distance the laser has moved), by first aligning the segments at the start and then recording the positional error accumulated by the end. The root-mean-square (RMS) errors are plotted as a function of traverse length in Figure 8. The observed RMS errors grow linearly with distance, at a rate of 2 to 5 percent of distance traveled. Inaccuracy in heading is the largest contributing source of error. Two of the datasets, Lucas and Mons Meg, exhibit relatively larger error growth rates, possibly due to the nature of the environments. Note that the same analysis carried out for the laser scanner trajectory rather than the handle trajectory results in drift rates of around two-thirds of a percent of distance traveled. The performance of the SLAM algorithm depends largely on the amount and type of $3 \mathrm{D}$ structure present. This behavior is somewhat different than in the case of traditional survey methods, where the accuracy depends more heavily on the equipment used and the surveyor's skill.

\section{Koonalda Cave}

Koonalda Cave is an archaeologically significant cave in the remote Nullarbor Plain in South Australia. The cave consists of two large interconnected chambers on two different levels (Fig. 9). The upper chamber is a fairly linear passage about $250 \mathrm{~m}$ in length and 15 to $30 \mathrm{~m}$ wide. The ceiling is domed, with a typical height ranging between 4 and $20 \mathrm{~m}$, and the floor contains many rockpiles primarily due to ceiling collapse. The lower chamber is T-shaped, with one major section running north-south and another east-west, and it contains several small lakes. The ceilings are generally higher than in the upper chamber, typically ranging between 10 and $30 \mathrm{~m}$. At their main junction, the lower chamber's floor is only a few meters below the upper chamber's, but ceiling collapse in the upper chamber has resulted in much of its floor being raised nearly $20-\mathrm{m}$ higher. The western end of the lower chamber contains a lake with a $23 \mathrm{~m}$ high roof, near the top of which a small balcony connects to the upper chamber through a narrow squeeze. The entry to Koonalda Cave is at the bottom of a $20 \mathrm{~m}$ deep sinkhole, which has an opening to the surface of approximately $60 \mathrm{~m}$ by $35 \mathrm{~m}$. 


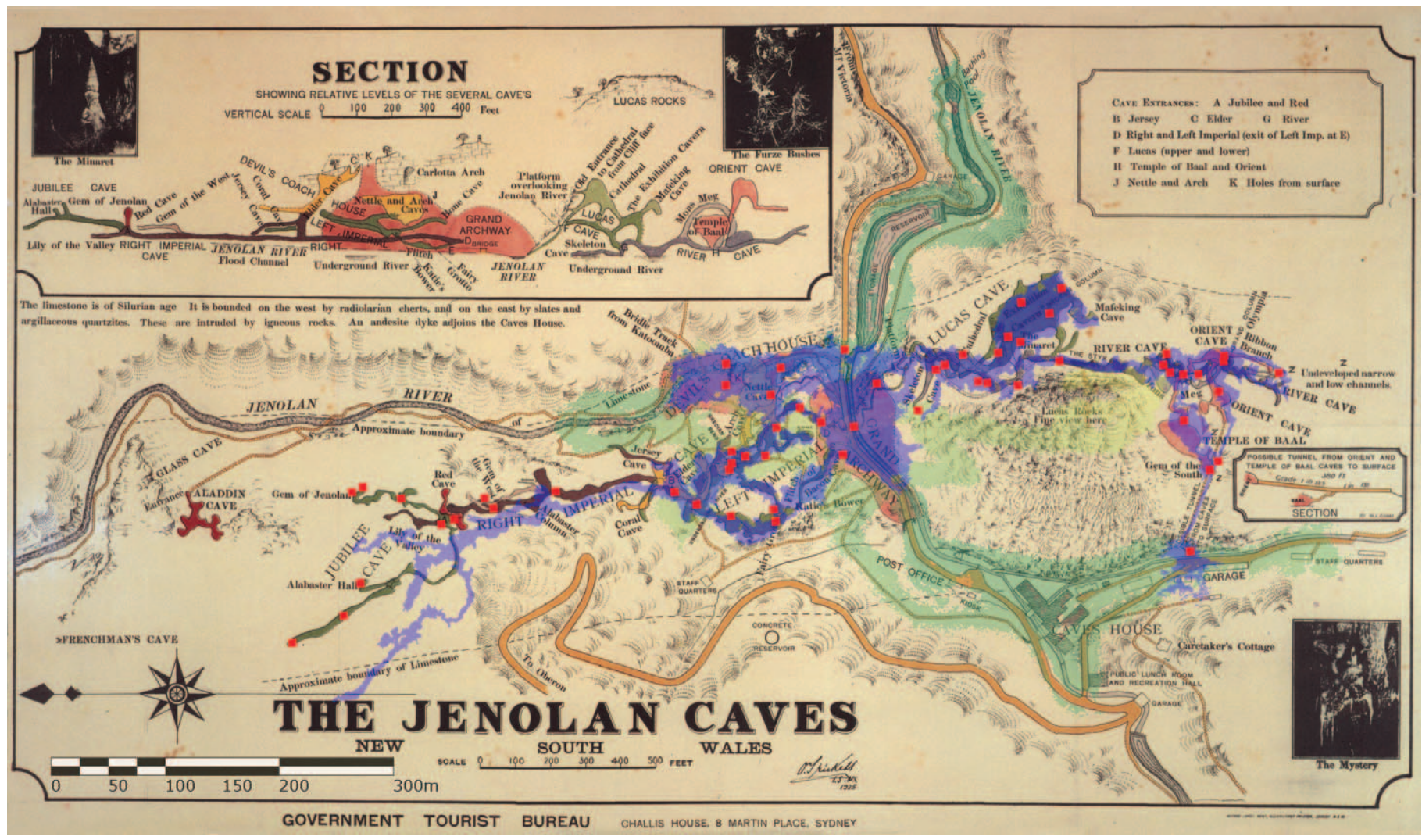

Figure 7. Comparison of Jenolan results with previous surveys. The Zebedee model is shaded in blue (caves) and green (exterior) and overlaid on the map produced by Trickett (1925). The red spots denote 59 survey stations from the Jenolan Caves Survey Project (1987-2005). The Zebedee trajectory has been rigidly aligned with the survey stations using a robust Iterative Closest Point algorithm, and the survey stations have been aligned to the Trickett map manually. The registration between the survey stations and the Zebedee trajectory has been applied using a rigid model to ensure that the presented Zebedee map is based on independent measurements only.

Unlike many of the caves at Jenolan, Koonalda Cave does not contain any significant speleothem formations, and typically it is fairly dry, with the notable exception of the lakes in the lower level.

Koonalda Cave has been the subject of archaeological and speleological study for several decades. We are working in collaboration with archaeologists from the South Australian Museum and Flinders University who are studying the cave and surrounding region. The cave contains evidence of human presence, including flint mining, believed to have occurred between 30,000 and 10,000 years ago. These visitors also left markings on some of the soft rock surfaces using fingers and other tools. The finger flutings form grooves about 3 to $5 \mathrm{~mm}$ deep that cover hundreds of square meters of the wall surfaces, which are in many places made up of a soft, powdery calcite material. It is expected that high-resolution 3D models of the cave will be valuable in providing data for remote archaeological and geomorphological study, as well as providing a virtual model that can be interactively explored, as the cave is not accessible to the public.
Our initial mapping expedition to Koonalda took place in November 2011, during which a single early Zebedee system was available and only the upper level was scanned. We returned to the cave in December 2012, when more complete scanning of both levels was performed with multiple Zebedee systems. Having multiple operators enabled the mapping team to scan different routes through the cave simultaneously, providing both redundancy and efficiency, as we could cover different sides of the many rockpiles more quickly in this manner. We estimate that it would be feasible to get an overall model of the cave structure using a single Zebedee system in under an hour, but we were aiming for fairly dense and complete coverage of all visible surfaces and therefore covered all reachable areas of the cave meticulously. In addition to the mapping team, the expedition included a team of archaeologists from the South Australian Museum, a photogrammetry researcher capturing the artwork in high-resolution detail, and representatives from the Mirning, who are the traditional owners of the land in which Koonalda resides. A significant portion of the data collection was performed 


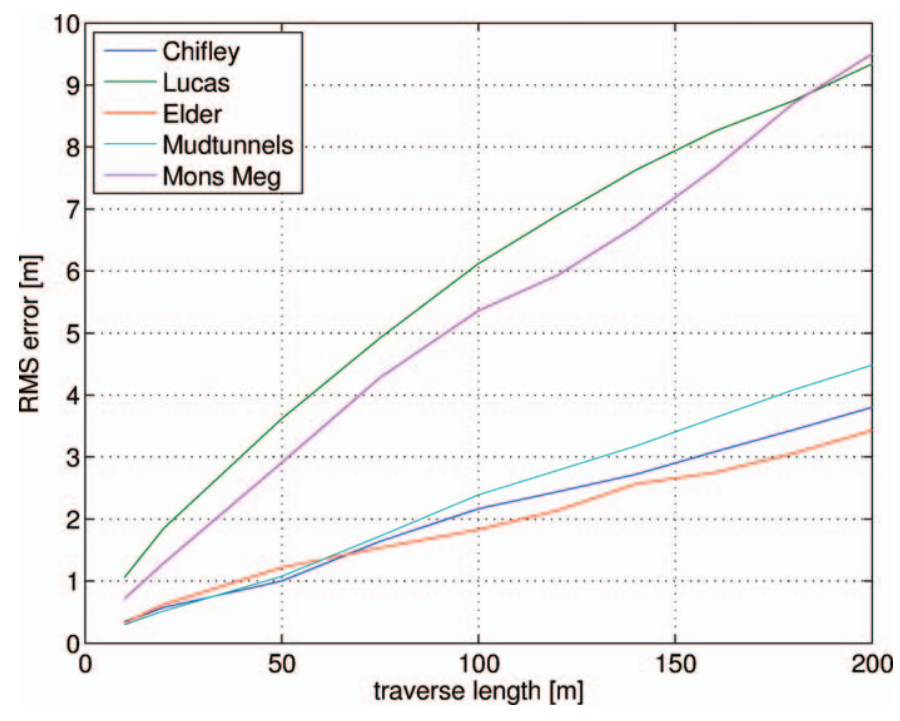

Figure 8. Positional root-mean-square (RMS) error curves calculated for five datasets, each of which forms part of a closed loop but is not itself a loop. The curves show the observed error as a function of the operator's traverse length, that is, the distance walked rather than the distance the swaying laser scanner traveled. For each dataset, the error is computed based on the difference between the endpoints of the open- and closed-loop solutions for different segment lengths of the Zebedee handle trajectory.

by one of the Mirning representatives, who successfully captured over an hour of data, predominantly covering the lower level of the cave, after one to two minutes of instruction on how to operate the system.

Figure 9 illustrates a full 3D map of the scanned area of the cave, including the sinkhole, the upper and lower levels, and the squeeze area. The squeeze is a $3 \mathrm{~m}$ long passage about $30 \mathrm{~cm}$ high connecting the northwest end of the upper level to a balcony above one of the lakes in the western end of the lower level. The data were recorded by three operators in a total of three hours of acquisition time, but less elapsed time due to the multiple units. The operators generally traversed the cave at a slow walking pace that varied somewhat based on local terrain. Visualizing the map in Figure 9 as a 3D model on screen can facilitate scientific modeling and analysis of various aspects of its history, including geomorphology, extent of former twilight zones, and possible former entrances. A comparative overlay between the 1976 survey map and the Zebedee 3D map is presented in Figure 10. The two maps are generally in agreement, though there is a slight angular difference at the squeeze. It is difficult to know which is closer to the true structure without further independent measurements; we note, however, that the Zebedee model closes a loop through measurements of the lower level from the balcony, and we are unaware of whether the traverse was closed in the 1976 survey. An example close-up view of an area in the upper level known as the Ramparts is presented in Figure 11. This rendering illustrates the level of detail available in the $3 \mathrm{D}$ point cloud data. In general, the density of the point cloud is a factor of how quickly the operator traverses the cave and how much time is spent scanning a particular area of interest. The lakes on the lower level of the cave (not shown in the figure) appear as empty areas in the point cloud, because the beam from the infrared laser is for the most part absorbed or specularly reflected by water, though it can penetrate where the water is sufficiently shallow.

\section{Conclusions}

We have introduced a new system that enables the application of mobile LiDAR mapping technology to surveying natural cave environments for the first time. The Zebedee 3D mapping system has been demonstrated in a variety of caves, with the most extensive results in Jenolan Caves and Koonalda Cave in Australia. The proposed method offers improvements over current practice and state-of-the-art technology in a number of ways. Mobility increases efficiency by transforming the mapping process into a continuous one in which a single person can survey a cave in approximately the same time it takes to traverse through it. The portability and flexibility of the equipment ensures that it can go nearly everywhere its operator can, including through tight squeezes, up ladders, and down abseils. Coverage of the environment is achieved through mobility, rather than worrying about viewpoint positioning as in the case of static terrestrial LiDAR. The equipment can be operated by non-experts with almost no training. In general, a brief coaching session is sufficient. In addition, workflow automation for both data acquisition and processing enables non-experts to generate 3D models directly from raw data and prevents errors that can occur with manual techniques. The $3 \mathrm{D}$ point cloud maps that are generated and the surface models that are created from them are significantly more detailed and accurate locally compared to traditional hand sketches and coarse 3D models based on left-down-up-right measurements at stations. Maps can also be transformed into a georeferenced coordinate frame if suitable control points within or GPS measurements outside the cave are available and can be associated with the existing data. While rough maps from traditional survey methods can be suitable for general navigation through a cave, for some applications, such as scientific research and environmental assessment, greater detail and resolution are required.

There are some limitations to the current system, several of which are being addressed as the technology progresses. Over large scales, the accuracy of the system can be lower than traditional methods applied with the best current equipment and expertise. We are working on advancements to the algorithms and hardware that should improve the system performance over time. The centimeter-scale precision of the range measurements of the Hokuyo scanner preclude the capture of fine details such 


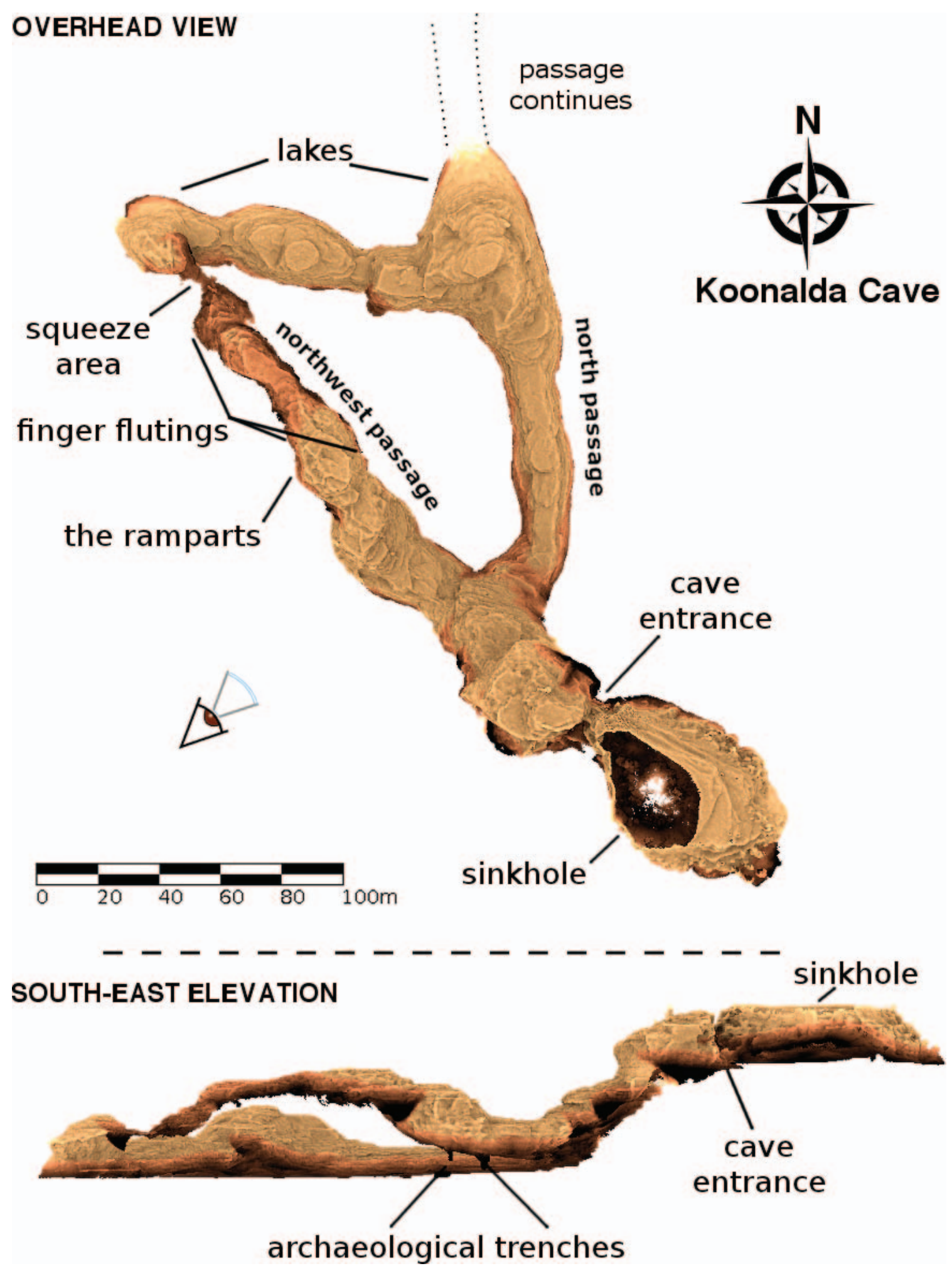

Figure 9. Three-dimensional map of Koonalda Cave generated using the Zebedee system. The eye icon indicates the viewing direction of the side elevation. Several areas of interest are marked. The model consists of approximately 300 million points, each of which is colored according to the relative local height above the cave floor. The point cloud was generated using five separate datasets representing under three hours of data collection, some of which was done in parallel by multiple operators. The survey of the north passage was not completed, as it contains deeper lakes and would have required a boat or other equipment to proceed. Two archaeological trenches are visible in the southeast elevation view. 


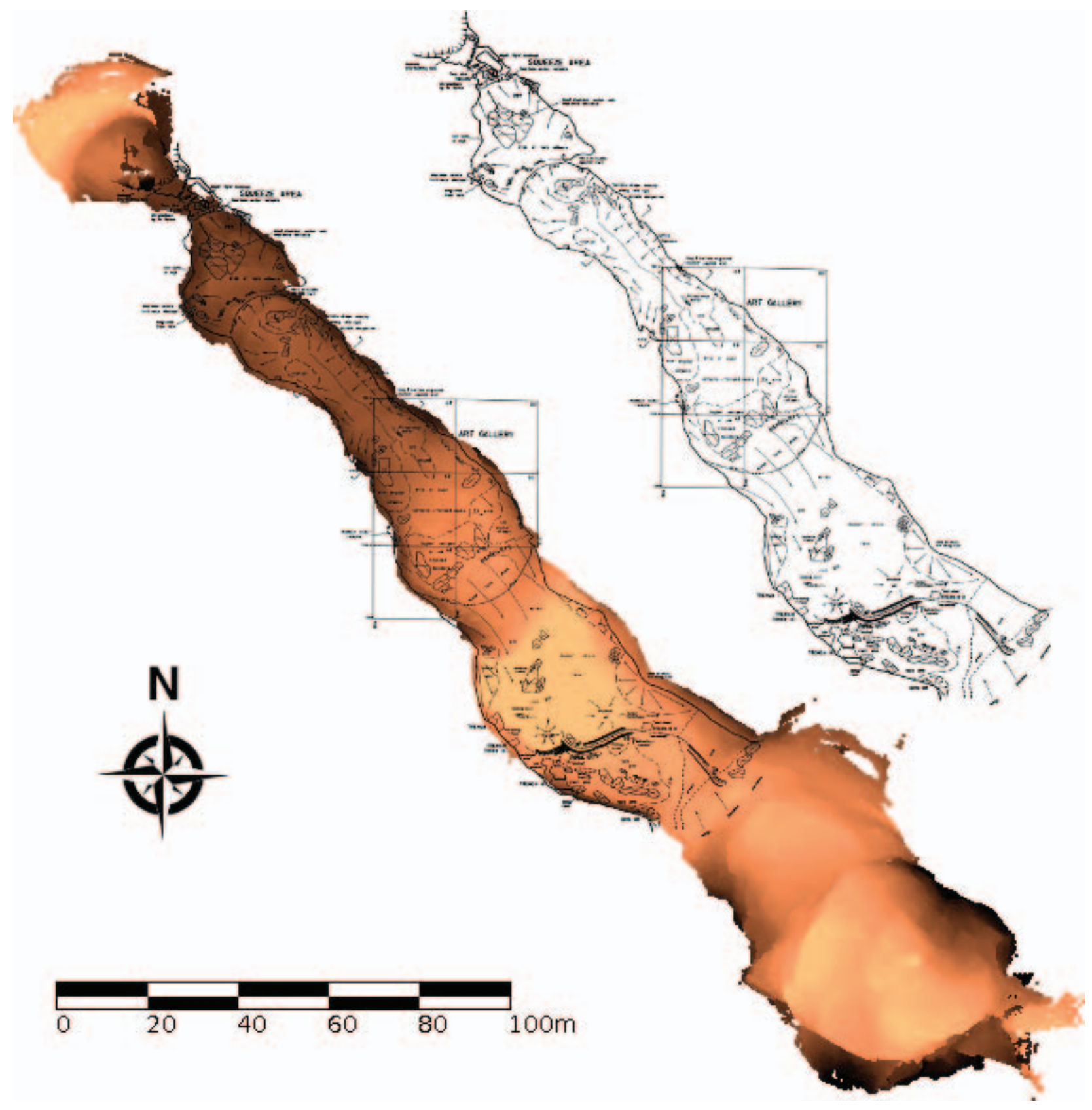

Figure 10. Overhead view of a 3D map of the upper level of Koonalda Cave generated with the Zebedee system. A line drawing from a 1976 map (using tacheometer, $5 \mathrm{~mm}$ graduated staff, and Suunto compass) has been manually overlaid for comparison. Some differences in the wall locations can be attributed to the fact that the 1976 survey was sketched at a particular height, whereas this view of the 3D map highlights the outer hull of the cave walls. Note the slight differences between the two maps in the upper left near the squeeze area. The 3D map consists of approximately 150 million points, each of which is colored according to the relative local height above the cave floor.

as the finger flutings at Koonalda and very thin speleothem features at Jenolan. However, in cases where these features are relatively localized, other techniques such as photogrammetry or static laser scanning can be used to produce high-resolution models that can be merged into the point cloud (photogrammetry is currently being investigated for modeling the finger flutings at Koonalda). Improvements in LiDAR technology could eventually result in a lightweight scanner with millimeter precision and other improved features that could seamlessly be incorporated into the Zebedee system. The existing equipment cannot be used underwater, though the core algorithms could be adapted for use with sonar or other suitable sensing modalities. In theory, there are some types of environments 


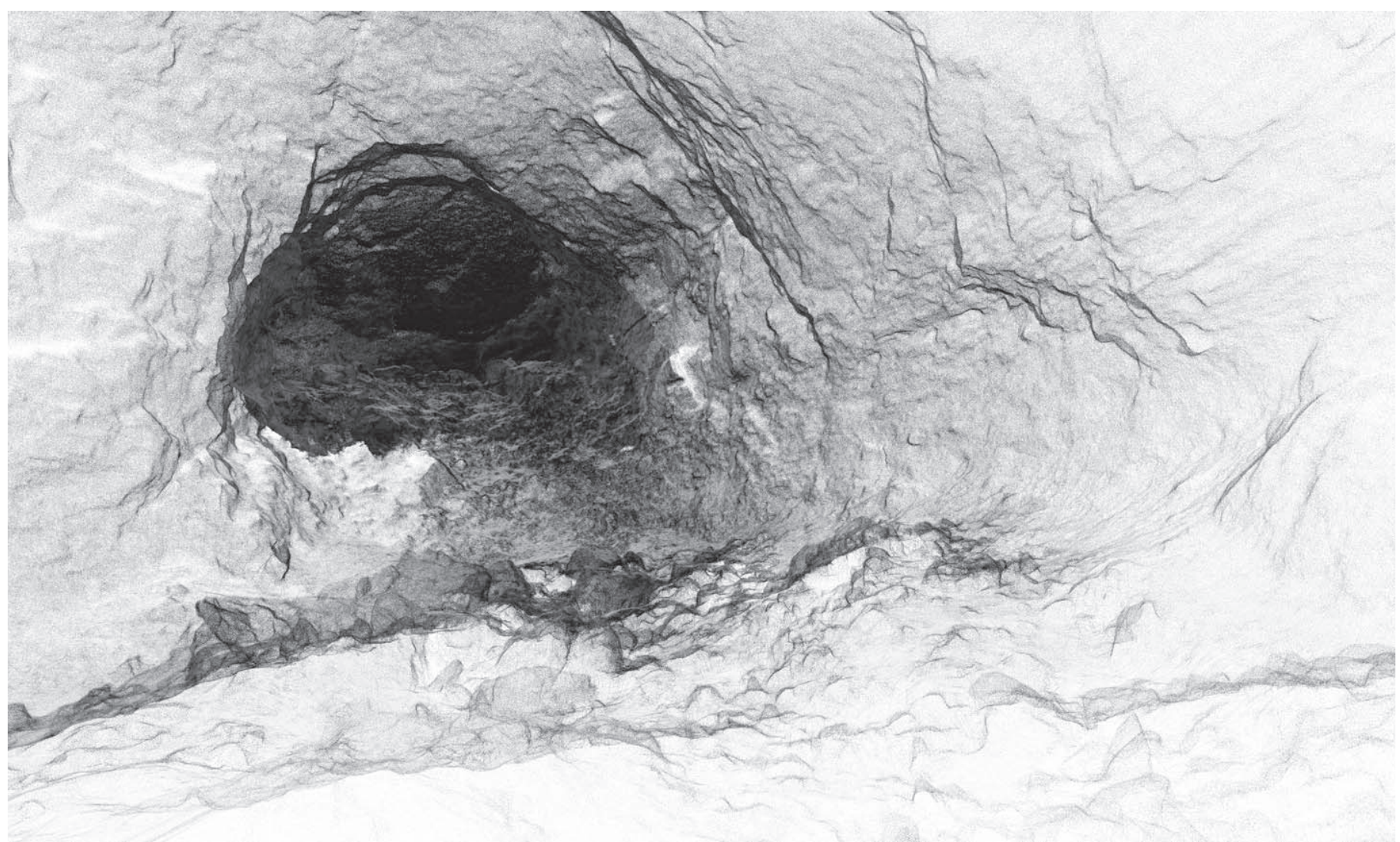

Figure 11. View of the 3D point cloud viewed from inside Koonalda Cave at the bottom of the Ramparts. In the foreground are several boulders, beyond which is a steep slope formed by significant ceiling collapse. The point cloud has been downsampled to $3 \mathrm{~cm}$ revolution.

that are theoretically troublesome for this technology, but these are not expected to occur in caves. For example, a very large (relative to the maximum scanning range) geometrically featureless void or a long, smooth tunnellike environment would make it difficult to estimate the scanner's motion in all dimensions. Finally, the hardware currently costs thousands of dollars, which may limit affordability for some cave survey applications.

Our data collection strategy thus far has primarily been intended to map the caves, and we did not specifically plan in experimental procedures that would provide a straightforward way to quantitatively compare the results with previous surveys. We intend to address this in upcoming field trips when we will collect dedicated datasets specifically for comparison purposes. We also plan to replace some of our earlier datasets with data collected from more up-to-date hardware, which we expect will improve the overall accuracy of the maps.

Two-dimensional plan and section maps are widely used for navigation through caves, and high-resolution 3D models are not necessarily suitable for this purpose. Further processing can be done to convert the 3D models into the standard 2D symbolic representations for printing out on paper. Another possibility is that $3 \mathrm{D}$ electronic or even solid representations of caves could become a standard navigation tool in the future. We are further investigating methods for colorizing the point clouds according to the visual appearance of the caves, and have recently generated preliminary results towards this goal by adding a small camera to the handheld unit.

Although Zebedee has been deployed across a wide range of mapping applications, including forests, mines, interiors and exteriors of buildings, and industrial sites, the concept was initially inspired by imagining how we could adapt larger, vehicle-borne technology into a form suitable for mapping caves. We envision that the availability of this technology will create new opportunities for scientific studies of natural caves that were previously impossible. The fact that the system can be fully automated also opens up the possibility that similar hardware can be deployed on robotic vehicles in cave environments too difficult or hazardous for human exploration.

\section{ACKNOWLEDGEMENTS}

We acknowledge the assistance and support of a number of individuals and organizations in making this work possible. Paul Flick is largely responsible for the mechan- 
ical and electronic design and assembly of both the Zebedee and Hannibal hardware platforms. We wish to acknowledge the traditional land owners of both of the cave sites visited.

Our 2010 field trip to the Jenolan Caves was partially supported by the Australian Nuclear Science and Technology Organisation (ANSTO).We wish to acknowledge in particular the contribution of Chris Waring there in helping to coordinate the fieldwork for multiple trips, assisting with data collection, and introducing the opportunity to map the caves. We thank the Jenolan Caves Reserve Trust and the many guides who have assisted our efforts over the years. The survey locations illustrated in Figure 7 are courtesy of the Jenolan Caves Survey Project. We also thank the Sydney Speleological Society and Jenolan Caves Historical and Preservation Society for assistance in locating source materials.

We wish to thank the Mirning People for their support and involvement with this project at Koonalda. Our work there has been partially supported by the Department of Industry, Innovation, Science, Research and Tertiary Education through an Inspiring Australia-Unlocking Australia's Potential grant and by the South Australian Museum. We wish to acknowledge Keryn Walshe of the SA Museum and Flinders University for inspiring this effort and coordinating the fieldwork. We also thank SA Parks \& Wildlife and the South Australian State Emergency Service for providing assistance with access and entry to the cave. The 1976 survey data appearing in Figure 10 was produced by I. D. Lewis and K. R. Mott, Cave Exploration Group South Australia and the SA Museum and provided courtesy of the SA Museum Archives/Archaeology/Gallus/Koonalda.

We also wish to thank and acknowledge Claude Holenstein, Ciril Baselgia, and Hans Moorkens of the Commonwealth Scientific and Industrial Research Organisation (CSIRO) for their contributions in developing the 3D surface reconstruction software used to generate the maps in Figure 4; Peyman Moghadam (CSIRO), Stuart Hankin (ANSTO), and Michael Laing (Mirning) for assistance with data collection; Elise Bosse for developing the web/smartphone interface to the Zebedee system; and Aaron Morris for initial inspiration towards addressing the challenge of mobile cave mapping.

\section{REFERENCES}

Baselgia, C., Bosse, M., Zlot, R., and Holenstein, C., 2014, Solid model reconstruction of large-scale outdoor scenes from 3D LiDAR data, in Yoshida, K., and Tadokoro, S., eds., Field and Service Robotics: Berlin, Springer Tracts in Advanced Robotics 92, p. 541-554. doi:10.1007/978-3-642-40686-7_36.

Bosse, M., and Zlot, R., 2009, Continuous 3D scan-matching with a spinning 2D laser, in ICRA '09: IEEE International Conference on Robotics and Automation, p. 4312-4319. doi:10.1109/ROBOT.2009. 5152851

Bosse, M., and Zlot, R., 2013, Place recognition using keypoint voting in large 3D LiDAR datasets, in 2013 IEEE International Conference on
Robotics and Automation (ICRA), p. 2677-2684. doi:10.1109/ ICRA.2013.6630945.

Bosse, M., Zlot, R., and Flick, P., 2012, Zebedee: Design of a springmounted 3D range sensor with application to mobile mapping: IEEE Transactions on Robotics, v. 28, no. 5, p. 1104-1119. doi:10.1109/ TRO.2012.2200990.

Canter, P., and Stott, A., 2011, Mapping interior spaces with speed, ease \& accuracy: The American Surveyor, v. 8 , no. 4

Davis, D.G., and Land, L., 2006, Recently discovered passages in Fort Stanton Cave, New Mexico, and implications for speleogenesis and regional geomorphic processes in the northern Sacramento Mountains, in Land, L., Lueth, V.W., Raatz, W., Boston, P., and Love, D.L., eds., Caves and Karst of Southeastern New Mexico: New Mexico Geological Society 57th Annual Field Conference, p. 219-226.

Dryjanskii, M., 2010, The subterranean world of Easter Island: GeoInformatics, v. 13 , no. 1 , p. 6-9.

Durrant-Whyte, H., and Bailey, T., 2006, Simultaneous localization and mapping (SLAM): Part I the essential algorithms: IEEE Robotics \& Automation Magazine, v. 13, no. 2, p. 99-110. doi:10.1109/MRA. 2006.1638022 .

Fairfield, N., Wettergreen, D., and Kantor, G., 2010, Segmented SLAM in three-dimensional environments: Journal of Field Robotics, v. 27, no. 1, p. 85-103. doi:10.1002/rob.20320.

Gary, M.O., Fairfield, N., Stone, W.C., Wettergreen, D., Kantor, G., and Sharp, Jr., J.M., 2008, 3D mapping and characterization of Sistema Zacatón from DEPTHX (DEep Phreatic THermal eXplorer), in Yuhr, L.B., Alexander, Jr., E.C., and Beck, B.F., eds., Proceedings of the 11th Multidisciplinary Conference on Sinkholes and Engineering and Environmental Impacts of Karst: American Society of Civil Engineers Geotechnical Special Publication no. 183, p. 202-212. doi:10.1061/ 41003(327)20.

Heeb, B., 2008, Paperless caving - an electronic cave surveying system, in Gonon, T., ed., Proceedings of the 4th European Speleological Congress, Vercors 2008: Lyon, Fédération française de spéléologie, Spelunca Mémoires 33, p. 130-133.

Holenstein, C., Zlot, R., and Bosse, M., 2011, Watertight surface reconstruction of caves from 3D LiDAR data, in 2012 IEEE/RSJ International Conference on Intelligent Robots and Systems, p. 3830-3837. doi:10.1109/IROS.2011.6095145.

Hunter, D., 2010, A field trial of common hand-held cave survey instruments and their readers, Bullita Cave System, July 2010: Caves Australia, no. 183, p. 10-12.

James, J.M., Martin, D.J., Tunnock, G.M., and Warild, A.T., 2009, A cave survey for research and tourist cave management, in White, W.B., ed., Proceedings 15th International Congress of Speleology: Huntsville, National Speleological Society, v. 3, p. 1381-1387.

Kershaw, B., 2012, Managing the survey information of the caves of Judbarra / Gregory National Park, Northern Territory: Helictite, v. 41, p. 87-94.

Liu, T., Carlberg, M., Chen, G., Chen, J., Kua, J., and Zakhor, A., 2010, Indoor localization and visualization using a human-operated backpack system, in Mautz, R., Kunz, M., and Ingensand, H., eds., Proceedings of the 2010 International Conference on Indoor Positioning and Indoor Navigation: IEEE, $10 \mathrm{p}$. doi:10.1109/ IPIN.2010.5646820.

McIntire, D., 2010, Laser scanning mushpot cave: The American Surveyor, v. 7, no. 9, p. 18-27.

Middleton, G.J., 1991, Oliver Trickett: Doyen of Australia's Cave Surveyors, 1847-1934: Sydney Speleological Society Occasional Paper no. $10,156 \mathrm{p}$.

Morris, A., Ferguson, D., Omohundro, Z., Bradley, D., Silver, D., Baker, C., Thayer, S., Whittaker, C., and Whittaker, W., 2006, Recent developments in subterranean robotics: Journal of Field Robotics, v. 23 , no. 1 , p. 35-57. doi:10.1002/rob.20106.

Nüchter, A., Surmann, H., Lingemann, K., Hertzberg, J., and Thrun, S., 2004, 6D SLAM with an application in autonomous mine mapping, in Proceedings, 2004 IEEE International Conference on Robotics and Automation, ICRA '04, p. 1998-2003. doi:10.1109/ROBOT.2004. 1308117.

Osborne, R.A.L., Zwingmann, H., Pogson, R.E., and Colchester, D.M., 2006, Carboniferous clay deposits from Jenolan Caves, New South Wales: implications for timing of speleogenesis and regional geology: Australian Journal of Earth Sciences, v. 53, no. 3, p. 377-405. doi:10.1080/08120090500507362. 
Petrie, G., 2010, Mobile mapping systems: An introduction to the technology: GeoInformatics, v. 13, no. 1, p. 32-43.

Rüther, H., Chazan, M., Schroeder, R., Neeser, R., Held, C., Walker, S., Matmon, A., and Howritz, L.K., 2009, Laser scanning for conservataion and research of African cultural heritage sites: The case study of Wonderwerk Cave, South Africa: Journal of Archaeological Science, v. 36, p. 1847-1856. doi:10.1016/j.jas.2009.04.012.

Sadier, B., Delannoy, J.-J., Benedetti, L., Bourlès, D.L., Jaillet, S., Geneste, J.-M., Lebatard, A.-E., and Arnold, M., 2012, Further constraints on the Chauvet cave artwork elaboration: Proceedings of the National Academy of Sciences of the United States of America, v. 109 , no. 21 , p. $8002-8006$. doi:10.1073/pnas.1118593109.

Slavova, T., 2012, Modern methods and devices for mapping underground galleries and natural caves, in Proceedings of the 4th International Conference on Cartography and GIS. 7 p.
Stone, W.C., am Elde, B.A., Wefer, F.L., and Jones, N.A., 2000, Automated 3D mapping of submarine tunnels, in Stone, W.C., ed., Robotics 2000: Fourth International Conference and Exposition/ Demonstration on Robotics for Challenging Situations and Environment American Society of Civil Engineers, p. 148-157. doi:10.1061/ 40476(299)19.

Warild, A., 2007, Vertical, 5th edn.: Alan Warild, 206 p.

Waring, C., Wilson, S., Hurry, S., and Griffith, D., 2009, Cave speleothem growth response to external weather from continuous cave atmosphere (CO2) and drip-water chemistry (DIC) isotopic measurement [abs.]: Geophysical Research Abstracts, v. 11, $11778 \mathrm{p}$.

Zlot, R., and Bosse, M., 2014, Efficient large-scale three-dimensional mobile mapping for underground mines: Journal of Field Robotics, v. 31, no. 5, p. $758-779$. doi:10.1002/rob.21504. 